\title{
SEISMIC PERFORMANCE OF CYLINDRICAL LATTICED-INTERSECTED-THREE-DIMENSIONAL- BEAM-SYSTEM RETICULATED MEGA-STRUCTURE WITH DOUBLE-LAYERS GRID SUB-STRUCTURES
}

\author{
Yongjun $\mathrm{He}^{1, *}$, Xuhong Zhou ${ }^{2}$, Shilin Dong ${ }^{3}$ and $\mathrm{Jia}^{1} \mathrm{i}^{1}$ \\ ${ }^{1}$ College of Civil Engineering of Hunan University, Changsha 410082, China; \\ *(Corresponding author: Email: hyj0087@163.com) \\ ${ }^{2}$ Chang'an University, Xi'an 710064, China; \\ ${ }^{3}$ Zhejiang University, Hangzhou 310027, China
}

\begin{abstract}
This paper is focused on the research of seismic response of cylindrical latticed-intersectedthree-dimensional-beam-system (LITDBS) reticulated mega-structure with double-layers plane-plate grid sub-structures using response spectrum technique. The distribution law of dynamic internal forces of members in this new structure is researched firstly. Reasonable number of vibration modes recommended for use is discussed. Seismic behaviors of the structure under different directional seismic loads are analyzed; therefore the reasonable required components of seismic loads for seismic design are obtained. A series of geometrical parameters analysis are carried out at last. All the works will provide guides in theory for the use of this structure.
\end{abstract}

Keywords: latticed-intersected-three-dimension-beam-system (LITDBS), mega-structure, plane-plate grid sub-structure, seismic response, vibration mode-decomposition-response-spectra method, parameters analysis

\section{INTRODUCTION}

Cylindrical latticed-intersected-three-dimensional-beam-system (LITDBS) reticulated megastructure with double-layers plane-plate grid sub-structures is an important style of reticulated mega-structure [1-3], which is a new structure meeting the need of super span for space structure. As showed in Figure 1, the whole structure is made up of two levels structures: the first level is the big grid structure called main structure which is made up of the arched 3d latticed beams (x-direction) and the longitudinal $3 \mathrm{~d}$ latticed beams (y-direction); the second level is the sub-structures which are double-layers plane-plate grids installed in big grids of the main structure generally. The main structure bears all of the loads and transfers them to the supporting structure. One sub-structure only bears the loads within the corresponding big grid and then transfers them to the main structure. Therefore a new structure of big grids filled with small grids is formed (for legible, many sub-structures are not showed in figure). The structure has been completely researched on its constitution, form parameters, supporting style, static property and stability in reference [2], it is fond that the main structure can be decided by six parameters as following: span of the main structure; rise; height of latticed 3d beam; number of big girds in the direction of arch; number of big girds in longitudinal direction; the number

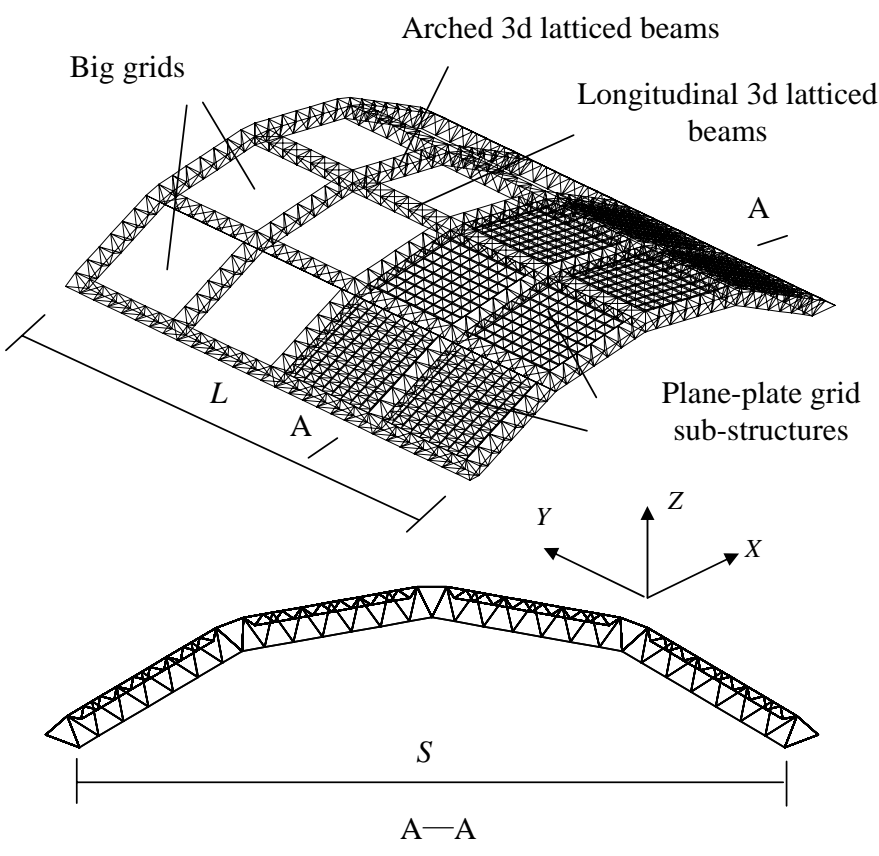

Figure 1. Cylindrical LITDBS reticulated mega-structure with double layer plane-plate grid substructures 
of mall grids in a latticed 3d beam segment within a big gird, and a program to form this structure automatically was developed based on these six parameters, but the seismic response property is not known. This paper is focused on the research of elastic seismic response property of cylindrical LITDBS reticulated mega-structure with double-layers plane-plate grid sub-structures.

Time history analysis is a direct dynamic analysis method, which can reflect the whole process state of the structure under keen earthquakes exactly and roundly. But the calculating course is excessive and complex. The response spectrum method is mostly used at present. Though the time history analysis exists in design codes in some countries, mainly it is a supplement for response spectrum method. So the response spectrum method is used in this paper and corresponding programs are worked out based on subspace iterative method for character of eigen-vibration and response spectrum method for seismic internal forces [4].

The distribution law of dynamic internal forces of members in this new structure is researched firstly; the reasonable combination of vibration modes and reasonable required components of seismic loads for seismic design are discussed; a series of geometrical parameters analysis are carried out at last. All the works will provide guides in theory for the use of this structure.

\section{ANALYSIS OF THE BASIC SEISMIC PROPERTY OF THE STRUCTURE}

\subsection{Basic seismic property of the main structure}

Assuming that the span of the main structure is $100 \mathrm{~m}$, ratio of height of arch to span is $1 / 5$, numbers of big grids is $5 \times 5$, the height of $3 \mathrm{~d}$ latticed beams is $3.5 \mathrm{~m}$, the number of grids in each $3 d$ latticed beam segment is 6 , the section of members in main structure is $\Phi 180 \times 10$, the thickness of the plane-plate grid sub-structure is $1.2 \mathrm{~m}$ and the section of members in it is $\Phi 76 \times 4$. The sub-structures are braced on main structure and the main structure is bound along the two longitudinal sides. The value of the vertical area load upon upper surface of the whole structure is 1 $\mathrm{kN} / \mathrm{m}^{2}$. The seismic response properties are calculated using vibration mode-decompositionresponse-spectra method; the loads are translated to the equivalent of point loads on nodes. The basic dynamic parameters are as follows: the seismic

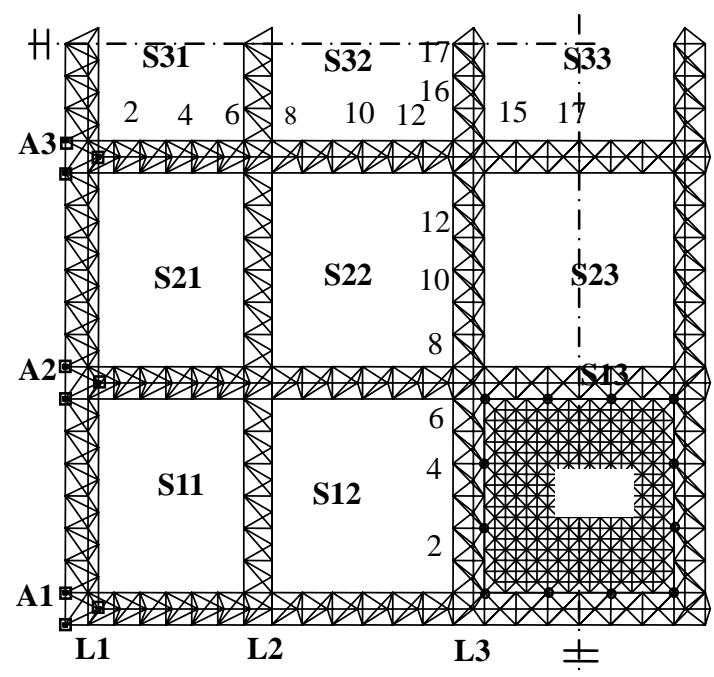

Figure 2. The schematic plan of the structure with codes of some sub-structures and members fortification intensity is 8 degree; near earthquake, class II site, which are referred to national criterion of China [5]. As many steel structural systems, 0.02 is adopted as the damping ratio of this structure. The three-dimensional earthquake action is considered.

The dynamic internal forces of corresponding members in the same position of parallel arched 3d latticed beams are listed in Tables 1 and 2 on both conditions of the main structure bearing the loads by itself and corporately with sub-structures. The codes " $n 1$ " and " $n 2$ " in tables represent positions of members in arches and codes of arched 3d latticed beams respectively (please see Figure 2); “UM”, “ LM", "UBM”, “UCM” and "WM” represent upper chord members, lower 
chord members, upper diagonal bracing members, upper crossbar members and web members in arched 3d latticed beams respectively. Contrasting Tables 1 and 2 we can see that the dynamic internal forces in members of arched 3d latticed beams especially in upper chord members and upper crossbar members at bottom and center are big relatively on condition of the main structure bearing the loads by itself. Mainly because the longitudinal stiffness is smaller than that in other directions on condition of the main structure bearing the loads by itself, the first vibration mode represents longitudinal vibration mostly [6]. And because the upper chord members are restricted with two parallel sustainers, dynamic internal forces in upper chord members at bottom and center of the arch especially near the sustainers are big remarkably when the structure vibrate in longitudinal direction. But the peak value of dynamic internal forces in lower chord members near the sustainers is not obvious because the single sustainer of lower chord member restrict longitudinal vibration little. On condition of the main structure bearing load corporately with sub-structures the dynamic internal forces of upper chord members and upper crossbar members at bottom and center decline evidently, but the dynamic internal forces of lower chord members at top of the arched 3d latticed beams increase evidently. The dynamic internal forces in upper and lower chord members of arched 3d latticed beams become homogeneous for the participation of sub-structures in bearing load.

Table 1. Comparison of dynamic internal forces in corresponding members of arched 3d latticed beams in different positions $(\mathrm{kN})$ (Main structure bearing load corporately with sub-structures)

\begin{tabular}{|c|c|c|c|c|c|c|}
\hline$n 1$ & $n 2$ & UM & LM & UBM & UCM & WM \\
\hline \multirow{3}{*}{$\begin{array}{c}1 \\
\text { (Bottom) }\end{array}$} & A1 & $23.2(0.065)$ & $43.3(0.065)$ & $27.5(1.517)$ & $19.4(1.764)$ & $9.3(0.141)$ \\
\cline { 2 - 7 } & A2 & $43.8(0.094)$ & $54.7(0.054)$ & $30.2(0.460)$ & $21.3(0.441)$ & $17.9(0.146)$ \\
\cline { 2 - 7 } & A3 & $49.9(0.103)$ & $70.2(0.068)$ & $31.1(0.390)$ & $22.0(0.377)$ & $21.9(0.186)$ \\
\hline \multirow{4}{*}{$\begin{array}{c}9 \\
\text { (Center) }\end{array}$} & A1 & $15.0(0.038)$ & $35.8(0.114)$ & $9.7(0.172)$ & $6.7(0.181)$ & $8.5(0.087)$ \\
\cline { 2 - 7 } & A2 & $29.7(0.052)$ & $48.0(0.118)$ & $18.2(0.409)$ & $14.3(0.081)$ & $11.6(0.079)$ \\
\cline { 2 - 7 } & A3 & $38.2(0.068)$ & $59.0(0.139)$ & $18.3(0.362)$ & $16.2(0.085)$ & $14.6(0.092)$ \\
\hline \multirow{3}{*}{$\begin{array}{c}17 \\
\text { (Top) }\end{array}$} & A1 & $20.1(0.047)$ & $35.0(3.035)$ & $2.3(0.049)$ & $1.6(0.044)$ & $4.0(0.092)$ \\
\cline { 2 - 7 } & A2 & $31.8(0.052)$ & $43.4(0.685)$ & $3.3(0.057)$ & $2.3(0.054)$ & $5.1(0.081)$ \\
\cline { 2 - 7 } & A3 & $41.5(0.067)$ & $58.6(1.783)$ & $4.0(0.067)$ & $3.0(0.067)$ & $6.0(0.095)$ \\
\hline
\end{tabular}

* Data in brackets represent ratio of dynamic to static internal members

Table 2. Comparison of dynamic internal forces in corresponding members of arched 3d latticed beams in different positions $(\mathrm{kN})$

(Main structure bearing load by itself)

\begin{tabular}{|c|c|c|c|c|c|c|}
\hline $\mathrm{n} 1$ & $\mathrm{n} 2$ & $\mathrm{UM}$ & $\mathrm{LM}$ & $\mathrm{UBM}$ & UCM & WM \\
\hline \multirow{3}{*}{$\begin{array}{c}1 \\
\text { (Bottom) }\end{array}$} & $\mathrm{A} 1$ & $121.3(0.379)$ & $24.3(0.035)$ & $39.5(1.503)$ & $27.9(1.368)$ & $10.9(0.206)$ \\
\cline { 2 - 7 } & $\mathrm{A} 2$ & $131.7(0.246)$ & $54.9(0.048)$ & $46.5(0.678)$ & $32.9(0.653)$ & $16.3(0.356)$ \\
\cline { 2 - 7 } & $\mathrm{A} 3$ & $138.8(0.248)$ & $76.4(0.065)$ & $47.1(0.655)$ & $33.3(0.632)$ & $21.0(0.641)$ \\
\hline \multirow{3}{*}{\begin{tabular}{c} 
Center $)$ \\
\cline { 2 - 7 }
\end{tabular}} & $\mathrm{A} 1$ & $29.1(0.074)$ & $29.7(0.084)$ & $29.6(1.077)$ & $20.3(0.510)$ & $6.9(0.097)$ \\
\cline { 2 - 7 } & $\mathrm{A} 2$ & $43.7(0.068)$ & $50.6(0.089)$ & $39.2(0.525)$ & $27.0(0.369)$ & $9.8(0.136)$ \\
\hline \multirow{2}{*}{$\begin{array}{c}17 \\
\text { (Top) }\end{array}$} & $\mathrm{A} 1$ & $52.2(0.080)$ & $69.7(0.116)$ & $37.8(0.471)$ & $26.2(0.339)$ & $12.2(0.169)$ \\
\cline { 2 - 7 } & $\mathrm{A} 2$ & $56.7(0.072)$ & $38.4(0.185)$ & $4.3(0.049)$ & $3.2(0.049)$ & $5.5(0.071)$ \\
\cline { 2 - 7 } & $\mathrm{A} 3$ & $67.5(0.082)$ & $54.3(0.280)$ & $5.7(0.061)$ & $4.2(0.062)$ & $7.3(0.092)$ \\
\hline
\end{tabular}

* Data in brackets represent ratio of dynamic to static internal members

We can see from the tables that the dynamic internal forces of the same kind of members in corresponding positions of arched 3d latticed beams increase gradually with the change of arches' locations from the end (A1) to the center (A3) of the whole structure, and the distribution laws of the dynamic internal forces of members in every parallel arches are the same, so this segment lays emphasis on the research of the central arched 3d latticed beam (A3). The distribution laws of the dynamic internal forces of members in every parallel longitudinal $3 \mathrm{~d}$ latticed beam are also analogous; so it is reasonable to lay emphasis on the research of the central longitudinal $3 \mathrm{~d}$ latticed beam (L2). 
To analyze in detail, the dynamic internal forces of members in A3 and L2 are listed in Table 3 and Table 4 respectively. The code " $D F_{\mathrm{m}}$ " and " $\xi$ " in tables represent the dynamic internal forces and ratios of dynamic to static internal force in members; " $n$ " represents the positions of members in the 3d latticed beams; "UM”, “ LM”, "UBM”, "UCM” and "WM” represent upper chord members, lower chord members, upper diagonal bracing members, upper crossbar members and web members in 3d latticed beam respectively.

Table 3. Distribution of dynamic internal forces and ratios of dynamic to static internal force in members of central arched 3d latticed beam

(Main structure bearing load corporately with sub-structures)

\begin{tabular}{|c|c|c|c|c|c|c|c|c|c|c|}
\hline \multirow{2}{*}{$n$} & \multicolumn{2}{|c|}{ UM } & \multicolumn{2}{|c|}{ LM } & \multicolumn{2}{c|}{ UBM } & \multicolumn{2}{c|}{ UCM } & \multicolumn{2}{|c|}{ WM } \\
\cline { 2 - 11 } & $\begin{array}{c}D F_{\mathrm{m}} \\
(\mathrm{kN})\end{array}$ & $\xi$ & $\begin{array}{c}D F_{\mathrm{m}} \\
(\mathrm{kN})\end{array}$ & $\xi$ & $\begin{array}{c}D F_{\mathrm{m}} \\
(\mathrm{kN})\end{array}$ & $\xi$ & $\begin{array}{c}D F_{\mathrm{m}} \\
(\mathrm{kN})\end{array}$ & $\xi$ & $\begin{array}{c}D F_{\mathrm{m}} \\
(\mathrm{kN})\end{array}$ & $\xi$ \\
\hline $0^{*}$ & 67.2 & 0.107 & 96.5 & 0.078 & 26.0 & 0.126 & 17.1 & 0.106 & 35.2 & 0.620 \\
\hline 1 & 49.9 & 0.103 & 70.2 & 0.068 & 31.1 & 0.390 & 22.0 & 0.377 & 21.9 & 0.186 \\
\hline 2 & 34.4 & 0.059 & 49.1 & 0.060 & 31.0 & 0.388 & 18.8 & 0.089 & 21.8 & 0.199 \\
\hline 3 & 30.3 & 0.060 & 45.9 & 0.058 & 21.0 & 0.413 & 14.7 & 0.389 & 18.9 & 0.525 \\
\hline 4 & 29.4 & 0.057 & 55.0 & 0.072 & 20.6 & 0.405 & 16.3 & 0.086 & 18.5 & 0.448 \\
\hline 5 & 30.3 & 0.058 & 72.2 & 0.080 & 22.1 & 0.501 & 15.4 & 0.466 & 16.1 & 0.237 \\
\hline 6 & 36.6 & 0.081 & 90.7 & 0.087 & 21.5 & 0.485 & 6.8 & 0.275 & 15.7 & 0.208 \\
\hline $7 *$ & 41.7 & 0.084 & 90.5 & 0.095 & 13.4 & 0.156 & 8.8 & 0.288 & 14.4 & 0.139 \\
\hline 8 & 40.4 & 0.081 & 74.1 & 0.109 & 19.2 & 0.380 & 13.3 & 0.351 & 14.6 & 0.092 \\
\hline 9 & 38.2 & 0.068 & 59.0 & 0.139 & 18.3 & 0.362 & 16.2 & 0.085 & 14.3 & 0.096 \\
\hline 10 & 33.8 & 0.063 & 46.2 & 0.138 & 14.3 & 0.282 & 9.8 & 0.257 & 12.1 & 1.704 \\
\hline 11 & 35.6 & 0.062 & 35.9 & 0.138 & 13.2 & 0.261 & 15.0 & 0.084 & 11.9 & 0.989 \\
\hline 12 & 35.7 & 0.059 & 34.6 & 0.100 & 14.3 & 0.266 & 9.7 & 0.242 & 12.9 & 0.899 \\
\hline 13 & 36.5 & 0.065 & 43.0 & 0.097 & 13.1 & 0.244 & 9.5 & 0.366 & 12.8 & 0.598 \\
\hline $14 *$ & 41.9 & 0.064 & 52.0 & 0.133 & 10.0 & 0.080 & 9.9 & 2.382 & 10.7 & 0.410 \\
\hline 15 & 37.6 & 0.066 & 53.9 & 0.258 & 5.9 & 0.097 & 3.9 & 0.087 & 10.1 & 0.106 \\
\hline 16 & 43.5 & 0.066 & 58.7 & 1.454 & 5.1 & 0.083 & 10.9 & 0.061 & 9.5 & 0.113 \\
\hline 17 & 41.5 & 0.067 & 58.6 & 1.783 & 4.0 & 0.067 & 3.0 & 0.067 & 6.0 & 0.095 \\
\hline
\end{tabular}

From Table 3 we can see that the upper and lower chord members of the arched $3 \mathrm{~d}$ latticed beam are the main bearing components under $3 d$ earthquake action. The biggest dynamic internal force exists in lower chord member at the bottom of the arch. The biggest dynamic internal force of upper chord member also exists at the bottom of the arch. In the 3d latticed beam segments at the bottom and center of the arch, the dynamic internal forces of the central members appear smallest locally. The dynamic internal forces of members in cross-area of the 3d latticed beams appear largest locally, and the gradient of dynamic internal forces is largest at the bottom of the arch and it is smallest at the top of the arch. Most ratios of dynamic to static internal force keep within 0.1. The dynamic internal forces of lower chord members are larger than that of upper chord members obviously, but the distribution law is the same as that in upper chord members. The ratios of dynamic to static internal forces of lower chord members in center and top of the arch are higher than that of upper chord members in the corresponding positions obviously, and the difference becomes larger and larger when the position becomes closer and closer to the top of the arch. Since static internal forces of lower chord members of the arch change from big to small evidently with the positions change from bottom to top [2], but the dynamic internal forces change little, so the ratios of dynamic to static internal forces changes remarkably. The ratios of dynamic to static internal forces of lower chord members in top of the arch reach to 1.78, which proves that the static internal forces are small but dynamic internal forces are large relatively; we must pay attention to their section design. The internal forces of upper diagonal bracing members are not large but the ratios of dynamic to static internal forces are large relatively, which proves that the upper diagonal bracing members play an important role in bearing dynamic loads. The dynamic internal forces of upper crossbar members are small and the distribution law is not clear, but the static internal forces of a few members are very small which induces their ratios of dynamic to static internal forces are large comparatively. 
The dynamic internal forces and ratios of dynamic to static internal forces in members of longitudinal 3d latticed beam (L2) are listed in Table 4, comparing Table 4 with Table 3 we can see that the seismic internal forces in members of longitudinal 3d latticed beams are less than that of arched 3d latticed beams. The largest dynamic internal forces of longitudinal 3d latticed beams exists almost in upper diagonal bracing members except in cross-area which proves that upper diagonal bracing members play an important role in bearing earthquake load. The largest dynamic internal force of longitudinal 3d latticed beams exists in upper crossbar members in cross-area, because these members are just the upper chord members of the arched $3 \mathrm{~d}$ latticed beams in this area. The dynamic internal forces of upper chord members of longitudinal 3d latticed beam

Table 4. Distribution of dynamic internal forces and ratios of dynamic to static internal force in members of central longitudinal 3d latticed beam (Main structure bearing load corporately with sub-structures)

\begin{tabular}{|c|c|c|c|c|c|c|c|c|c|c|}
\hline \multirow{2}{*}{$n$} & \multicolumn{2}{|c|}{ UM } & \multicolumn{2}{|c|}{ LM } & \multicolumn{2}{c|}{ UBM } & \multicolumn{2}{c|}{ UCM } & \multicolumn{2}{|c|}{ WM } \\
\cline { 2 - 12 } & $\begin{array}{c}D F_{\mathrm{m}} \\
(\mathrm{kN})\end{array}$ & $\xi$ & $\begin{array}{c}D F_{\mathrm{m}} \\
(\mathrm{kN})\end{array}$ & $\xi$ & $\begin{array}{c}D F_{\mathrm{m}} \\
(\mathrm{kN})\end{array}$ & $\xi$ & $\begin{array}{c}D F_{\mathrm{m}} \\
(\mathrm{kN})\end{array}$ & $\xi$ & $\begin{array}{c}D F_{\mathrm{m}} \\
(\mathrm{kN})\end{array}$ & $\xi$ \\
\hline $0^{*}$ & 7.9 & 2.238 & 2.7 & 0.046 & 12.0 & 0.680 & 23.7 & 0.059 & 8.1 & 0.191 \\
\hline 1 & 17.3 & 0.239 & 6.04 & 0.051 & 19.4 & 4.249 & 13.7 & 1.866 & 6.7 & 0.447 \\
\hline 2 & 6.4 & 0.067 & 10.1 & 0.061 & 19.4 & 1.874 & 14.1 & 0.216 & 6.5 & 0.289 \\
\hline 3 & 12.4 & 0.128 & 10.0 & 0.067 & 16.4 & 0.914 & 11.6 & 0.690 & 6.3 & 0.253 \\
\hline 4 & 9.06 & 0.106 & 9.5 & 0.079 & 16.4 & 0.691 & 12.7 & 0.177 & 6.3 & 0.499 \\
\hline 5 & 8.9 & 0.119 & 5.8 & 0.168 & 18.7 & 0.338 & 13.2 & 0.306 & 7.0 & 0.147 \\
\hline 6 & 12.5 & 0.619 & 6.9 & 0.107 & 18.7 & 0.306 & 29.1 & 0.059 & 7.2 & 0.126 \\
\hline $7 *$ & 6.3 & 1.069 & 7.4 & 0.087 & 11.2 & 0.127 & 35.1 & 0.068 & 12.1 & 0.262 \\
\hline 8 & 16.2 & 0.415 & 3.2 & 0.178 & 20.7 & 3.550 & 14.6 & 1.774 & 8.5 & 0.594 \\
\hline 9 & 8.8 & 0.131 & 8.4 & 0.234 & 20.7 & 1.781 & 13.0 & 0.132 & 8.2 & 2.043 \\
\hline 10 & 12.5 & 0.228 & 8.4 & 0.234 & 17.0 & 1.476 & 12.0 & 0.980 & 7.0 & 0.460 \\
\hline 11 & 11.5 & 0.213 & 7.6 & 0.331 & 17.0 & 0.982 & 12.7 & 0.149 & 7.0 & 1.085 \\
\hline 12 & 9.1 & 0.228 & 2.5 & 0.057 & 20.2 & 0.407 & 14.3 & 0.365 & 8.0 & 0.204 \\
\hline 13 & 14.7 & 0.851 & 9.8 & 0.080 & 20.2 & 0.365 & 39.6 & 0.080 & 8.7 & 0.180 \\
\hline $14 *$ & 7.8 & 0.282 & 10.8 & 0.083 & 13.4 & 0.156 & 43.8 & 0.087 & 14.4 & 2.490 \\
\hline 15 & 15.9 & 0.707 & 6.3 & 0.115 & 20.6 & 3.49 & 14.6 & 3.844 & 9.4 & 0.361 \\
\hline 16 & 10.5 & 0.204 & 11.9 & 1.394 & 20.6 & 3.880 & 13.2 & 0.133 & 8.0 & 0.531 \\
\hline 17 & 13.8 & 0.305 & 12.4 & 0.818 & 17.1 & 2.456 & 12.1 & 1.340 & 7.0 & 0.523 \\
\hline
\end{tabular}

fluctuate but have no regularity and appear smallest locally in cross-area. The ratios of dynamic to static internal force are large comparatively though the dynamic internal forces are small and the largest ratio can reach above 2 . The dynamic internal forces of lower chord members are less than that of upper chord members in the same position; and appear local maximum in the center of every longitudinal 3d latticed beam. The ratios of dynamic to static internal forces are small except few members in the middle of the longitudinal 3d latticed beam. The upper diagonal bracing members are the main bearing components of longitudinal 3d latticed beams under the earthquake action, in which dynamic internal forces in the middle of cross-area are small but appear local maximum in the position near to cross-area. The ratios of dynamic to static internal forces are large, most of which are above 1.0, some one reach to 4.0. The dynamic internal forces of the upper crossbar members are large comparatively and fluctuate along the axial direction of the longitudinal 3d latticed beam, appearing wave crest in the cross-area with the arched 3d latticed beams and appearing wave trough in the middle of every $3 d$ latticed beam segment. The ratios of dynamic to static internal forces of upper crossbar members are high comparatively but not uniform. The dynamic internal forces in web members are small comparatively and all keep within $10 \mathrm{kN}$ except members in the cross-area. The ratios of dynamic to static internal force are still high comparatively. In a word, compared with the arched 3d latticed beam, the dynamic internal forces in longitudinal 3d latticed beams are all small comparatively but the ratios of dynamic to static internal forces are high comparatively for their static internal forces are very small. So we must pay attention to the dynamic checking calculation of these members after design according to static loads. 
Comparing Table 3 and Table 4 we can see that as the main bearing components the ratios of dynamic to static internal forces in upper and lower chord members of arched 3d latticed beams are almost kept within 0.1 which proves that the seismic property of this structure are good. Though the ratios of dynamic to static internal force in some upper diagonal brace members, upper cross-bar members, web members of arched 3d latticed beams and some members of longitudinal 3d latticed beams are high, their dynamic and static internal forces are all very small, which make it possible to design these members according to constructional demands.

\subsection{Distribution law of dynamic internal forces in sub-structures}

As sub-structures of the reticulated mega structure, the plane-plate girds have two functions: one is to bear the loads within their corresponding big grids, The other is to brace the main structure and bear the loads cooperatively with main structure. The calculation results show that the distribution laws of dynamic internal forces of different sub-structures at the same height are very alike and the numerical values are close to each other, but that of different sub-structures at different heights from bottom to top of the whole structure are unlike. So in this segment the different sub-structures at different heights from bottom to top such as S31, S32, and S33 (please see Figure 2) are researched. The upper chord members of sub-structures in arch direction are combined as folded linear arches by the upper crossbar members of longitudinal 3d latticed beams. Results of static analysis show that these parallel folded linear arches are the main bearing components of sub-structures while cooperating with main structure and their internal forces are greatly larger than other members of sub-structures. But the distribution laws of dynamic internal forces are different from that of static internal forces. The web members especially at bottom and center of sub-structures also become the main bearing components under the earthquake action. Dynamic internal forces of web members are larger than upper and lower chord members in central and bottom of sub-structures. The dynamic internal forces of web members become small gradually from low to upside in a sub-structure. The dynamic internal forces of web members in the corresponding position of different sub-structures become small gradually as the sub-structure's positions change from low to upside, At the top of the whole structure, the dynamic internal forces become very small and the chord members become the main bearing components. The ratios of dynamic to static internal force in members of sub-structures especially at bottom and center of the whole structure are large comparatively and many reach above 1.0, some one to 10 . Concrete numerical values are not listed here.

\section{ANALYSIS OF SEISMIC BEHAVIORS OF THE STRUCTURE UNDER DIFFERENT DIRECTIONAL EARTHQUAKE ACTION}

The seismic response behaviors of different structures under different directional earthquake waves are different. So the directions of earthquake wave that should be considered for designing different structure are different either. As to the cylindrical LITDBS reticulated mega-structure braced with plane-plate grids sub-structures, for the difference in stiffness, geometrical character between the main structure and sub-structures must cause the different sensitivities of the whole structure to different directional earthquake waves. This segment analyzes the distribution law of dynamic internal forces of the structure under different directional earthquake waves and determines the directions of earthquake waves that should be laid emphasis on accordingly.

Take the structure that geometrical parameters, restrictions, loads and the sections of components are the same as the structure showed in segment 1 to analyze. Different combinations of three 
directional earthquake waves such as horizontal transverse (X), longitudinal (Y) and vertical $(\mathrm{Z})$ are considered, and the results are listed in Tables 5, 6, and 7. In tables the codes " $D F_{\mathrm{m}}$ " and " $D F_{\mathrm{s}}$ " represent the dynamic internal forces of members in main structure and sub-structures respectively. Taking the dynamic internal forces under three-dimensional earthquake waves as the accurate value, the percentages of different values of dynamic internal forces under one-dimensional or two-dimensional earthquake waves to the accurate value represent the error. The values of error reflect the degree of approximation of substituting one-dimensional or two-dimensional result for the accurate value.

Table 5. Comparison of dynamic internal forces in main structure under earthquake action with different components

(Main structure bearing load corporately with sub-structures)

\begin{tabular}{|c|c|c|c|c|c|c|c|}
\hline \multirow{3}{*}{$\begin{array}{l}\text { Earth- } \\
\text { quake } \\
\text { wave }\end{array}$} & \multirow{3}{*}{$\begin{array}{c}\text { Compared } \\
\text { target }\end{array}$} & \multicolumn{6}{|c|}{ Positions of members } \\
\hline & & \multicolumn{2}{|c|}{4} & \multicolumn{2}{|c|}{10} & \multicolumn{2}{|c|}{16} \\
\hline & & $\mathrm{UM}^{*}$ & $\mathrm{LM}^{*}$ & UM & LM & UM & $\mathrm{LM}$ \\
\hline $3 \mathrm{~d}$ & $D F_{\mathrm{m}}(\mathrm{kN})$ & 29.36 & 54.95 & 33.77 & 46.22 & 43.54 & 58.68 \\
\hline \multirow{2}{*}{$X-1 d$} & $D F m(\mathrm{kN})$ & 6.18 & 14.65 & 8.76 & 34.70 & 2.41 & 6.84 \\
\hline & Error & $78.9 \%$ & $73.5 \%$ & $74.1 \%$ & $24.9 \%$ & $94.5 \%$ & $88.3 \%$ \\
\hline \multirow{2}{*}{ Y-1d } & $D F_{\mathrm{m}}(\mathrm{kN})$ & 10.16 & 1.59 & 2.74 & 1.51 & 6.86 & 1.14 \\
\hline & Error & $65.4 \%$ & $97.1 \%$ & $91.9 \%$ & $96.7 \%$ & $84.2 \%$ & $98.1 \%$ \\
\hline \multirow{2}{*}{ Z-1d } & $D F_{\mathrm{m}}(\mathrm{kN})$ & 26.63 & 52.93 & 32.42 & 30.50 & 42.91 & 58.27 \\
\hline & Error & $9.3 \%$ & $3.7 \%$ & $3.4 \%$ & $34.0 \%$ & $1.5 \%$ & $0.7 \%$ \\
\hline \multirow{2}{*}{$X Z-2 d$} & $D F_{\mathrm{m}}(\mathrm{kN})$ & 27.41 & 54.92 & 33.58 & 46.20 & 42.99 & 58.66 \\
\hline & Error & $6.6 \%$ & $0.05 \%$ & $0.6 \%$ & $0.04 \%$ & $1.3 \%$ & $0.03 \%$ \\
\hline \multirow{2}{*}{ YZ-2d } & $D F_{\mathrm{m}}(\mathrm{kN})$ & 28.63 & 52.96 & 32.61 & 30.54 & 43.47 & 58.28 \\
\hline & Error & $2.5 \%$ & $3.6 \%$ & $3.4 \%$ & $33.9 \%$ & $0.2 \%$ & $0.7 \%$ \\
\hline \multirow{2}{*}{ XY-2d } & $D F_{\mathrm{m}}(\mathrm{kN})$ & 12.30 & 14.74 & 9.42 & 34.73 & 7.35 & 6.93 \\
\hline & Error & $58.1 \%$ & $73.2 \%$ & $72.1 \%$ & $24.9 \%$ & $83.1 \%$ & $88.2 \%$ \\
\hline
\end{tabular}

*UM and LM represent upper and lower chord members respectively

From the results of Table 5 we can see that, on condition of the main structure bearing the load corporately with sub-structures, compared with the three-dimensional results, the $\mathrm{X}$-one-dimensional or Y-one-dimensional results are all very small and most of the error percentages are above $70 \%$. But under vertical earthquakes most of Z-one-dimensional results are close to the accurate values; the error percentages are within $10 \%$. Only the percentages of lower chord members at the half-height position of the arch reach to 34\%. Comparing the dynamic internal forces under one-dimensional earthquake wave of $\mathrm{X}, \mathrm{Y}$ and $\mathrm{Z}$ direction we can see that the response of the main structure to vertical earthquake wave exceeds greatly that to horizontal earthquake wave, so vertical component of the earthquake should be considered, but it is not enough for the largest error percentages of lower chord members at the half-height position of the arch reach to $34 \%$. When we consider YZ-two-dimensional earthquake wave, the largest error percentages reach to 33.9\%, which cannot meet the needs. But when we consider XZ-two-dimensional earthquake wave, most of the result error percentages keep within 1\% except that the largest error percentages of few upper chord members at the bottom of the arch reach to $6.6 \%$, which can meet the needs.

The results of sub-structures on condition of the main structure bearing the load corporately with sub-structures are listed in Table 6, from which we can see that the dynamic internal forces of members in different positions are irregular under different directional one-dimensional earthquake waves. Most of error percentages of X-one-dimensional results reach to $90 \%$. While only considering Y-directional one-dimensional earthquake wave, the error percentages of web members in central or lower position of sub-structures are $0 \%$, which proves that the dynamic internal forces of web members in central or lower position of sub-structures are caused by the longitudinal one-dimensional earthquake action, but the error percentages of upper and lower chord members can reach to $90 \%$. While only considering vertical one-dimensional earthquake wave, the error 
percentages of upper and lower chord members in central or lower position of sub-structures decline greatly and keep within $10 \%$, but the error percentages of web members reach to $95 \%$. So it is not enough only to consider one-dimensional earthquake action. If considering XZ-two-dimensional earthquake action, the error percentages of chord members decline greatly and keep within $0.5 \%$, but the error percentages of web members in central or lower position of sub-structures are still 90\%. While considering XY-two-dimensional earthquake action, result error percentages of many chord members reach to $90 \%$, which cannot meet the needs obviously. While considering YZ-two-dimensional earthquake action the largest error percentages of chord members in central or lower position of sub-structures reach to $12.1 \%$, but that of other members are small comparatively. We can see that the dynamic internal forces of members at the top of sub-structures are determined by the vertical earthquake action, which is similar to the seismic response property of general plane-plate grids structure. The responses of sub-structures at different height under earthquake waves from different directions are different for their different slopes. So it is not enough to get the real response results of the whole structure by only considering one-dimensional or two-dimensional earthquake action, and it is necessary to consider three-dimensional earthquake action for safety. While considering XZ-two-dimensional earthquake action, the largest error percentage of members in main structure is $6.6 \%$ and many of the error percentages are very small, the error percentages of chord members in sub-structures are all kept within 1\%, but that of web members in sub-structures are very large. Generally, the dynamic and static internal forces of web members in sub-structures are all small comparatively, and their cross-sections are redundant though they are designed according to construction demands, so we can only lay emphasis on seismic design of members in main structure and chord members in sub-structures, and we can only consider the XZ-two-dimensional earthquake wave.

Table 6. Comparison of dynamic internal forces in sub-structures under earthquake action with different components

(Main structure bearing load corporately with sub-structures)

\begin{tabular}{|c|c|c|c|c|c|c|c|c|c|c|}
\hline \multirow{3}{*}{$\begin{array}{l}\text { Earth- } \\
\text { quake } \\
\text { wave }\end{array}$} & \multirow{3}{*}{$\begin{array}{c}\text { Compared } \\
\text { target }\end{array}$} & \multicolumn{9}{|c|}{ Codes of sub-structures } \\
\hline & & \multicolumn{3}{|c|}{ S31 (Bottom) } & \multicolumn{3}{|c|}{ S32 (Center) } & \multicolumn{3}{|c|}{ S33 (Top) } \\
\hline & & $\mathrm{UM}^{*}$ & WM & LM & UM* $^{*}$ & WM & LM & $\mathrm{UM}^{*}$ & WM & LM \\
\hline $3 \mathrm{~d}$ & $D F_{\mathrm{s}}(\mathrm{kN})$ & 3.98 & 10.88 & 4.63 & 6.52 & 7.31 & 6.20 & 7.85 & 0.17 & 6.01 \\
\hline \multirow{2}{*}{$X-1 d$} & $D F_{s}(\mathrm{kN})$ & 1.29 & 0.15 & 2.21 & 1.33 & 0.03 & 0.35 & 0.01 & 0.01 & 0.00 \\
\hline & Error & $67.6 \%$ & $98.6 \%$ & $47.9 \%$ & $79.6 \%$ & $99.6 \%$ & $94.4 \%$ & $99.9 \%$ & $94.1 \%$ & $100 \%$ \\
\hline \multirow{2}{*}{ Y-1d } & $D F_{s}(\mathrm{kN})$ & 0.24 & 10.88 & 0.17 & 0.15 & 7.31 & 0.13 & 0.06 & 0.04 & 0.01 \\
\hline & Error & $94.0 \%$ & $0.0 \%$ & $96.3 \%$ & $97.7 \%$ & $0.0 \%$ & $97.9 \%$ & $99.2 \%$ & $76.5 \%$ & $0.2 \%$ \\
\hline \multirow{2}{*}{ Z-1d } & $D F_{s}(\mathrm{kN})$ & 3.76 & 0.18 & 4.07 & 6.38 & 0.25 & 6.19 & 7.85 & 0.17 & 6.01 \\
\hline & Error & $5.5 \%$ & $98.3 \%$ & $12.1 \%$ & $2.1 \%$ & $96.6 \%$ & $0.2 \%$ & $0.0 \%$ & $0.0 \%$ & $0.0 \%$ \\
\hline \multirow{2}{*}{$X Z-2 d$} & $D F_{s}(\mathrm{kN})$ & 3.97 & 0.24 & 4.63 & 6.51 & 0.25 & 6.20 & 7.85 & 0.17 & 6.01 \\
\hline & Error & $0.3 \%$ & $97.8 \%$ & $0.0 \%$ & $0.2 \%$ & $96.6 \%$ & $0.0 \%$ & $0.0 \%$ & $0.0 \%$ & $0.0 \%$ \\
\hline \multirow{2}{*}{ YZ-2d } & $D F_{s}(\mathrm{kN})$ & 3.77 & 10.88 & 4.07 & 6.38 & 7.31 & 6.19 & 7.85 & 0.17 & 6.01 \\
\hline & Error & $5.3 \%$ & $0.0 \%$ & $12.1 \%$ & $2.1 \%$ & $0.0 \%$ & $0.2 \%$ & $0.0 \%$ & $0.0 \%$ & $0.0 \%$ \\
\hline \multirow{2}{*}{$\mathrm{XY}-2 \mathrm{~d}$} & $D F_{s}(\mathrm{kN})$ & 1.31 & 10.88 & 2.22 & 1.34 & 7.31 & 0.38 & 0.06 & 0.04 & 0.01 \\
\hline & Error & $67.1 \%$ & $0.0 \%$ & $52.1 \%$ & $79.4 \%$ & $0.0 \%$ & $93.9 \%$ & $99.2 \%$ & $76.4 \%$ & $0.2 \%$ \\
\hline
\end{tabular}

The results of main structure on condition of the main structure bearing the load by itself are listed in Table 7, from which we can see that the largest error percentage of dynamic internal forces of members under X-one-dimensional or Y-one-dimensional earthquake action all are above $90 \%$ and the vertical seismic internal forces are still the main component of response value. But the largest error percentage of vertical one-dimensional results reach to $35.5 \%$. If considering two-dimensional earthquake action, the largest error percentage of XZ-two-dimensional results reach to $22.4 \%$ and the largest error percentage of YZ-two-dimensional results reach to 35.3\%, which all cannot meet the needs. So it is necessary to consider three-dimensional earthquake action for seismic design on condition of the main structure bearing loads by itself. 
Table 7. Comparison of dynamic internal forces in main structure under earthquake action with different components

(Main structure bearing load by itself)

\begin{tabular}{|c|c|c|c|c|c|c|c|}
\hline \multirow{3}{*}{$\begin{array}{l}\text { Earth- } \\
\text { quake } \\
\text { wave }\end{array}$} & \multirow{3}{*}{$\begin{array}{c}\text { Compared } \\
\text { target }\end{array}$} & \multicolumn{6}{|c|}{ Positions of members } \\
\hline & & \multicolumn{2}{|c|}{4 (bottom) } & \multicolumn{2}{|c|}{10 (center) } & \multicolumn{2}{|c|}{ 16（top） } \\
\hline & & *UM & LM & UM & LM & UM & LM \\
\hline $3 d$ & $D F_{\mathrm{m}}(\mathrm{kN})$ & 43.50 & 64.15 & 46.81 & 56.28 & 64.16 & 54.48 \\
\hline \multirow{2}{*}{$X-1 d$} & $D F m(\mathrm{kN})$ & 14.35 & 19.11 & 13.16 & 42.90 & 4.92 & 8.03 \\
\hline & Error & $67.0 \%$ & $70.2 \%$ & $71.9 \%$ & $23.8 \%$ & $92.3 \%$ & $85.3 \%$ \\
\hline \multirow{2}{*}{ Y-1d } & $D F_{\mathrm{m}}(\mathrm{kN})$ & 21.91 & 2.83 & 21.10 & 3.00 & 40.37 & 0.50 \\
\hline & Error & $49.6 \%$ & $95.6 \%$ & $54.9 \%$ & $94.7 \%$ & $37.1 \%$ & $99.1 \%$ \\
\hline \multirow{2}{*}{ Z-1d } & $D F_{\mathrm{m}}(\mathrm{kN})$ & 30.31 & 61.17 & 39.56 & 36.31 & 49.47 & 53.89 \\
\hline & Error & $30.3 \%$ & $4.6 \%$ & $15.5 \%$ & $35.5 \%$ & $22.9 \%$ & $1.1 \%$ \\
\hline \multirow{2}{*}{$\mathrm{XZ}-2 \mathrm{~d}$} & $D F_{\mathrm{m}}(\mathrm{kN})$ & 37.23 & 64.09 & 41.70 & 56.20 & 49.77 & 54.48 \\
\hline & Error & $14.4 \%$ & $0.1 \%$ & $10.9 \%$ & $0.1 \%$ & $22.4 \%$ & $0.0 \%$ \\
\hline \multirow{2}{*}{ YZ-2d } & $D F_{\mathrm{m}}(\mathrm{kN})$ & 41.06 & 61.23 & 44.91 & 36.44 & 63.93 & 53.89 \\
\hline & Error & $5.6 \%$ & $4.6 \%$ & $4.1 \%$ & $35.3 \%$ & $0.4 \%$ & $1.1 \%$ \\
\hline \multirow{2}{*}{$\mathrm{XY}-2 \mathrm{~d}$} & $D F_{\mathrm{m}}(\mathrm{kN})$ & 26.26 & 19.32 & 24.97 & 43.00 & 40.76 & 8.04 \\
\hline & Error & $39.6 \%$ & $69.9 \%$ & $46.7 \%$ & $23.6 \%$ & $36.5 \%$ & $85.2 \%$ \\
\hline
\end{tabular}

*UM and LM represent upper and lower chord members respectively

\section{RESEARCH ON THE REASONABLE COMBINATION OF VIBRATION MODES}

Based on the theory of vibration mode-decomposition-response-spectra method, generally in civil engineering, we can only consider the combination of the first several modes for seismic checking calculation of the structure. But the necessary number of vibration modes is different for different structures. The cylindrical LITDBS reticulated mega-structure with plane-plate grids sub-structures is a new structure. The difference in stiffness between the main structure and sub-structures leads to its complex vibration modes. The reasonable number of vibration modes for seismic design is not known, so this problem is researched in this segment. Taking the structure in Figure 2 for example, calculate the first thirty order modes and taking the dynamic internal forces from the combination of the first thirty modes as the accurate value. Then take different numbers of vibration modes in turn to calculate the dynamic internal forces and compare the results with the accurate value, from which we can know how many vibration modes should be taken to calculate the dynamic internal forces. Here the combinations numbers of vibration modes are 3, 6, 9, 12, 15, 16, 18, 25, 30 in turn. The geometrical parameters, restrictions, loads and the sections of components of the structure are the same as that showed in segment 1 .

The calculating results of upper chord members, lower chord members, upper brace members in center of the arched 3d latticed beam (A3) with different combined numbers of vibration modes are listed in Tables 8, 9 and 10 (Please see Figure 2 for the members positions). The calculating results of upper chord members, web members in sub-structures are listed in Table 11. The code " $n$ " in tables represents the number of combined vibration modes; "a" represents the dynamic internal forces; "b" represents the error of the calculating results compared with the accurate value, its calculating method are showed as formula (1).

$$
b(i)=\frac{a(30)-a(i)}{a(30)} \times 100 \%
$$

where $i$ represents the number of combined vibration modes. 
Table 8. Comparison of calculating dynamic internal forces in upper chord members of arched 3d latticed beam with different combined vibration modes

(Main structure bearing load corporately with sub-structures)

\begin{tabular}{|c|c|c|c|c|c|c|c|c|c|c|c|c|}
\hline \multirow{3}{*}{$n$} & \multicolumn{10}{c|}{ Positions of members } \\
\cline { 2 - 15 } & \multicolumn{2}{|c|}{1} & \multicolumn{1}{|c|}{4} & \multicolumn{2}{|c|}{7} & \multicolumn{2}{|c|}{10} & \multicolumn{2}{|c|}{13} & \multicolumn{2}{|c|}{16} \\
\cline { 2 - 14 } & $\begin{array}{c}\mathrm{a} \\
\mathrm{kN})\end{array}$ & $\begin{array}{c}\mathrm{b} \\
(\%)\end{array}$ & $\begin{array}{c}\mathrm{a} \\
(\mathrm{kN})\end{array}$ & $\begin{array}{c}\mathrm{b} \\
(\%)\end{array}$ & $\begin{array}{c}\mathrm{a} \\
(\mathrm{kN})\end{array}$ & $\begin{array}{c}\mathrm{b} \\
(\%)\end{array}$ & $\begin{array}{c}\mathrm{a} \\
(\mathrm{kN})\end{array}$ & $\begin{array}{c}\mathrm{b} \\
(\%)\end{array}$ & $\begin{array}{c}\mathrm{a} \\
(\mathrm{kN})\end{array}$ & $\begin{array}{c}\mathrm{b} \\
(\%)\end{array}$ & $\begin{array}{c}\mathrm{a} \\
(\mathrm{kN})\end{array}$ & $\begin{array}{c}\mathrm{b} \\
(\%)\end{array}$ \\
\hline 3 & 36.66 & 27.2 & 12.66 & 56.9 & 6.76 & 83.8 & 17.14 & 49.4 & 30.93 & 15.4 & 41.78 & 4.28 \\
\hline 6 & 47.05 & 6.52 & 16.63 & 43.4 & 15.15 & 63.7 & 17.59 & 48.1 & 33.93 & 7.19 & 42.34 & 3.00 \\
\hline 9 & 47.45 & 5.7 & 29.07 & 1.02 & 40.49 & 3.04 & 33.07 & 2.39 & 36.34 & 0.60 & 43.45 & 0.46 \\
\hline 12 & 47.52 & 5.58 & 29.32 & 0.17 & 40.89 & 2.08 & 33.35 & 1.56 & 36.38 & 0.49 & 43.45 & 0.46 \\
\hline 15 & 47.54 & 5.54 & 29.32 & 0.17 & 40.89 & 2.08 & 33.36 & 1.53 & 36.40 & 0.44 & 43.53 & 0.27 \\
\hline 16 & 49.95 & 0.76 & 29.36 & 0.03 & 41.72 & 0.10 & 33.77 & 0.32 & 36.51 & 0.14 & 43.54 & 0.25 \\
\hline 18 & 49.95 & 0.76 & 29.37 & 0.0 & 41.73 & 0.07 & 33.77 & 0.32 & 36.51 & 0.14 & 43.54 & 0.25 \\
\hline 25 & 49.95 & 0.76 & 29.37 & 0.0 & 41.73 & 0.07 & 33.78 & 0.30 & 36.51 & 0.14 & 43.54 & 0.25 \\
\hline 30 & 50.33 & - & 29.37 & - & 41.76 & - & 33.88 & - & 36.56 & - & 43.65 & - \\
\hline
\end{tabular}

Table 9. Comparison of calculating dynamic internal forces in lower chord members of arched 3d latticed beam with different combined vibration modes

(Main structure bearing load corporately with sub-structures)

\begin{tabular}{|c|c|c|c|c|c|c|c|c|c|c|c|c|}
\hline \multirow{3}{*}{$n$} & \multicolumn{12}{|c|}{ Positions of members } \\
\hline & \multicolumn{2}{|c|}{1} & \multicolumn{2}{|c|}{4} & \multicolumn{2}{|c|}{7} & \multicolumn{2}{|c|}{10} & \multicolumn{2}{|c|}{13} & \multicolumn{2}{|c|}{16} \\
\hline & $\begin{array}{c}\mathrm{a} \\
(\mathrm{kN})\end{array}$ & \begin{tabular}{|c|}
$\mathrm{b}$ \\
$(\%)$
\end{tabular} & $\begin{array}{c}\mathrm{a} \\
(\mathrm{kN})\end{array}$ & $\begin{array}{l}\mathrm{b} \\
\text { (\%) }\end{array}$ & $\begin{array}{c}\mathrm{a} \\
(\mathrm{kN})\end{array}$ & $\begin{array}{c}\mathrm{b} \\
(\%)\end{array}$ & $\begin{array}{c}\mathrm{a} \\
(\mathrm{kN})\end{array}$ & $\begin{array}{l}\mathrm{b} \\
\text { (\%) }\end{array}$ & $\begin{array}{c}\mathrm{a} \\
(\mathrm{kN})\end{array}$ & $\begin{array}{l}\text { b } \\
(\%)\end{array}$ & $\begin{array}{c}\mathrm{a} \\
(\mathrm{kN})\end{array}$ & $\begin{array}{c}\mathrm{b} \\
(\%)\end{array}$ \\
\hline 3 & 31.55 & 55.4 & 52.61 & 4.62 & 86.11 & 5.44 & 42.45 & 8.61 & 26.62 & 39.1 & 33.99 & 42.5 \\
\hline 6 & 31.66 & 55.2 & 52.64 & \begin{tabular}{|l|l}
4.57 \\
\end{tabular} & 86.14 & 5.40 & 42.49 & 8.53 & 26.70 & 38.9 & 34.01 & 42.5 \\
\hline 9 & 67.35 & 4.79 & 53.82 & 2.43 & 88.24 & 3.10 & 44.22 & 4.8 & 42.03 & 3.81 & 58.14 & 1.72 \\
\hline 12 & 67.96 & 3.93 & 53.83 & 2.41 & 88.26 & 3.07 & 44.28 & 4.7 & 42.33 & 3.16 & 58.63 & 0.90 \\
\hline 15 & 67.97 & 3.92 & 53.85 & 2.37 & 88.32 & 3.01 & 44.31 & 4.6 & 42.35 & 3.11 & 58.65 & 0.86 \\
\hline 16 & 70.16 & 0.82 & 54.95 & \begin{tabular}{|l|l|}
0.38 \\
\end{tabular} & 90.53 & 0.58 & 46.22 & 0.50 & 42.96 & 1.72 & 58.68 & 0.81 \\
\hline 18 & 70.16 & 0.82 & 54.96 & 0.36 & 90.53 & 0.58 & 46.23 & 0.47 & 42.98 & 1.67 & 58.68 & 0.81 \\
\hline 25 & 70.16 & 0.82 & 54.96 & 0.36 & 90.53 & 0.58 & 46.23 & 0.47 & 42.98 & 1.67 & 58.68 & 0.81 \\
\hline 30 & 70.74 & - & 55.16 & - & 91.06 & - & 46.45 & - & 43.71 & - & 59.16 & \\
\hline
\end{tabular}

Table 10. Comparison of calculating dynamic internal forces in upper diagonal brace members of arched 3d latticed beam with different combined vibration modes

(Main structure bearing load corporately with sub-structures)

\begin{tabular}{|c|c|c|c|c|c|c|c|c|c|c|c|c|}
\hline \multirow{3}{*}{$n$} & \multicolumn{10}{|c|}{ Positions of members } \\
\cline { 2 - 15 } & \multicolumn{2}{|c|}{1} & \multicolumn{2}{|c|}{4} & \multicolumn{2}{|c|}{7} & \multicolumn{2}{|c|}{10} & \multicolumn{2}{|c|}{13} & \multicolumn{2}{c|}{16} \\
\cline { 2 - 14 } & $\begin{array}{c}\mathrm{a} \\
(\mathrm{kN})\end{array}$ & $\begin{array}{c}\mathrm{b} \\
(\%)\end{array}$ & $\begin{array}{c}\mathrm{a} \\
(\mathrm{kN})\end{array}$ & $\begin{array}{c}\mathrm{b} \\
(\%)\end{array}$ & $\begin{array}{c}\mathrm{a} \\
(\mathrm{kN})\end{array}$ & $\begin{array}{c}\mathrm{b} \\
(\%)\end{array}$ & $\begin{array}{c}\mathrm{a} \\
(\mathrm{kN})\end{array}$ & $\begin{array}{c}\mathrm{b} \\
(\%)\end{array}$ & $\begin{array}{c}\mathrm{a} \\
(\mathrm{kN})\end{array}$ & $\begin{array}{c}\mathrm{b} \\
(\%)\end{array}$ & $\begin{array}{c}\mathrm{a} \\
(\mathrm{kN})\end{array}$ & $\begin{array}{c}\mathrm{b} \\
(\%)\end{array}$ \\
\hline 3 & 5.32 & 82.9 & 2.47 & 88.0 & 1.66 & 87.6 & 1.53 & 89.3 & 2.33 & 82.3 & 3.23 & 37.4 \\
\hline 6 & 30.86 & 0.93 & 20.45 & 0.82 & 11.25 & 16.2 & 13.95 & 2.4 & 12.51 & 4.79 & 4.36 & 15.5 \\
\hline 9 & 30.98 & 0.55 & 20.52 & 0.48 & 13.13 & 2.23 & 14.20 & 0.63 & 12.87 & 2.05 & 4.45 & 13.8 \\
\hline 12 & 31.03 & 0.39 & 20.60 & 0.10 & 13.23 & 1.49 & 14.27 & 0.14 & 13.05 & 0.68 & 4.46 & 13.6 \\
\hline 15 & 31.04 & 0.35 & 20.60 & 0.10 & 13.24 & 1.41 & 14.27 & 0.14 & 13.10 & 0.30 & 5.06 & 1.94 \\
\hline 16 & 31.13 & 0.06 & 20.62 & 0.0 & 13.41 & 0.15 & 14.28 & 0.07 & 13.10 & 0.30 & 5.07 & 1.74 \\
\hline 18 & 31.14 & 0.03 & 20.62 & 0.0 & 13.43 & 0.0 & 14.28 & 0.07 & 13.10 & 0.30 & 5.07 & 1.74 \\
\hline 25 & 31.14 & 0.03 & 20.62 & 0.0 & 13.43 & 0.0 & 14.28 & 0.07 & 13.13 & 0.08 & 5.12 & 0.77 \\
\hline 30 & 31.15 & - & 20.62 & - & 13.43 & - & 14.29 & - & 13.14 & - & 5.16 & - \\
\hline
\end{tabular}

From the result in tables we can see that the dynamic internal forces in members increase as the increasing of the number of combined vibration modes, which do not increase equably. The main increases of dynamic internal forces are focused within the first nine order modes. From Tables 8, 9 and 10, we can see that the largest error percentage of upper chord members in arched 3d latticed beam reach to $60 \%$ and that of lower chord members reach to $50 \%$ while considering six combined vibration modes. But considering nine combined vibration modes the error percentage of upper and lower chord members decline greatly. The error percentages of all upper chord members at the bottom of arch except one reaching to $5.7 \%$ are kept within 5\%, which can meet the needs. The error percentages of most upper brace members are kept within $3 \%$. The error percentages of a few 
upper brace members in top of arch reach to $13.8 \%$, but the dynamic internal forces of members in this position are small comparatively so it is not the key position of seismic design. From Table 11 we can see that the error percentages of members in sub-structures keep within $10 \%$ while considering nine combined vibration modes, and the error percentages of members with larger dynamic internal forces are small comparatively. The error percentages of members with smaller dynamic internal forces are large comparatively. So while using the vibration mode-decompositionresponse-spectra method to calculate the seismic behaviors the result error percentages of main bearing components keep within 5\% if considering nine combined vibration modes, which can meet the needs basically. The error of calculating result of dynamic internal forces decline step by step with the increase of combined vibration modes. If considering sixteen vibration modes, as main bearing components, the error percentages of dynamic internal forces in upper chord members of the arched 3d latticed beam keep within 1\%, and that in most of lower chord members keep within 1\% except few members at center and top of the arch, and that in most of upper brace members keep within $0.5 \%$ except few members at top of the arch. The error percentages of dynamic internal forces in members of sub-structures all keep within 3\% and those in web members are $0 \%$.

Table 11. Comparison of calculating dynamic internal forces in members of sub-structures with different combined vibration modes (Main structure bearing load corporately with sub-structures)

\begin{tabular}{|c|c|c|c|c|c|c|c|c|c|c|c|c|}
\hline \multirow{4}{*}{$n$} & \multicolumn{10}{|c|}{ Positions of sub-structures } \\
\cline { 2 - 14 } & \multicolumn{3}{|c|}{ S31 (bottom) } & \multicolumn{3}{c|}{ S32 (center) } & \multicolumn{3}{c|}{ S33 (top) } \\
\cline { 2 - 14 } & $*$ UM & \multicolumn{2}{c|}{ WM } & \multicolumn{2}{c|}{ UM } & \multicolumn{2}{c|}{ WM } & \multicolumn{2}{c|}{ UM } & \multicolumn{2}{c|}{ WM } \\
\cline { 2 - 14 } & $\begin{array}{c}\mathrm{a} \\
(\mathrm{kN})\end{array}$ & $\begin{array}{c}\mathrm{b} \\
(\%)\end{array}$ & $\begin{array}{c}\mathrm{a} \\
(\mathrm{kN})\end{array}$ & $\begin{array}{c}\mathrm{b} \\
(\%)\end{array}$ & $\begin{array}{c}\mathrm{a} \\
(\mathrm{kN})\end{array}$ & $\begin{array}{c}\mathrm{b} \\
(\%)\end{array}$ & $\begin{array}{c}\mathrm{a} \\
(\mathrm{kN})\end{array}$ & $\begin{array}{c}\mathrm{b} \\
(\%)\end{array}$ & $\begin{array}{c}\mathrm{a} \\
(\mathrm{kN})\end{array}$ & $\begin{array}{c}\mathrm{b} \\
(\%)\end{array}$ & $\begin{array}{c}\mathrm{a} \\
(\mathrm{kN})\end{array}$ & $\begin{array}{c}\mathrm{b} \\
(\%)\end{array}$ \\
\hline 3 & 0.49 & 87.9 & 0.11 & 99.0 & 3.00 & 55.0 & 0.23 & 88.1 & 7.20 & 10.4 & 0.14 & 17.6 \\
\hline 6 & 0.55 & 86.4 & 10.84 & 0.4 & 3.01 & 54.9 & 7.29 & 0.3 & 7.26 & 9.7 & 0.15 & 11.8 \\
\hline 9 & 3.66 & 9.4 & 10.84 & 0.4 & 6.30 & 5.5 & 7.29 & 0.3 & 7.67 & 4.6 & 0.17 & 0.0 \\
\hline 12 & 3.79 & 6.2 & 10.88 & 0.0 & 6.45 & 3.3 & 7.31 & 0.0 & 7.68 & 4.5 & 0.17 & 0.0 \\
\hline 15 & 3.79 & 6.2 & 10.88 & 0.0 & 6.49 & 2.7 & 7.31 & 0.0 & 7.85 & 2.4 & 0.17 & 0.0 \\
\hline 16 & 3.98 & 1.5 & 10.88 & 0.0 & 6.52 & 2.2 & 7.31 & 0.0 & 7.85 & 2.4 & 0.17 & 0.0 \\
\hline 18 & 4.02 & 0.5 & 10.88 & 0.0 & 6.52 & 2.2 & 7.31 & 0.0 & 7.85 & 2.4 & 0.17 & 0.0 \\
\hline 25 & 4.04 & 0.0 & 10.88 & 0.0 & 6.53 & 2.1 & 7.31 & 0.0 & 7.86 & 2.2 & 0.17 & 0.0 \\
\hline 30 & 4.04 & - & 10.88 & - & 6.67 & - & 7.31 & - & 8.04 & - & 0.17 & - \\
\hline
\end{tabular}

*UM and WM represent upper chord members and web members respectively

Changing the geometrical parameters such as ratios of rise to span or length to span of the main structure, height of latticed 3d beam, height of substructures etc within a reasonable range can reach similar conclusion (the concrete data omitted). So considering both main structure and the sub-structures, for seismic calculating of the cylindrical LITDBS reticulated mega-structure with plane-plate grids sub-structures using vibration mode-decomposition-response-spectra method, the error percentages of dynamic internal forces of the main bearing components keep within $5 \%$ if considering nine vibration modes, which can meet the needs basically. If condition permits we can consider the first sixteen vibration modes, the error percentages of dynamic internal forces of the main bearing components keep within $1 \%$.

\section{ANALYSIS ON PARAMETERS OF STRUCTURE}

The cylindrical LITDBS reticulated mega-structure with plane-plate grids sub-structures has several shape parameters such as ratio of rise to span of the main structure, ratio of length to span, height of 3d latticed beam and the thickness of sub-structures etc. The influence of these parameters on dynamic internal forces in members of the structure is researched in this segment. Take the maximum of absolute values as target to analyze. Suppose that the vertical uniform loads act on the 
top surface of the whole structure and transfer them to equivalent of lumped masses on nodes. The main structure is bound along the two longitudinal sides (See the black block in Figure 2). The meanings of codes in the following segments are as follows:

$S$ : span of the main structure, $f$ : ratio of rise to span of the main structure, $m$ : number of big grids in arched direction, $a$ : size of big grids, $h$ : height of $3 d$ latticed beam, $h s$ : thickness of sub-structures, Load: vertical uniform loads, Sm: sectional dimension of members in main structure, Ss: sectional dimension of members in sub-structures.

\subsection{Influence of ratio of rise to span $-\mathbf{f}$}

Suppose that: $S=100 \mathrm{~m}, \quad m=5, h=3.5 \mathrm{~m}$, $S m=\Phi 180 \times 10, h s=1.2 \mathrm{~m}, \quad S s=\Phi 76 \times 4$, Load $=1 \mathrm{kN} / \mathrm{m}^{2}$, numbers of upper chord grids of sub-structures are $9 \times 9$. Different values of ratio of rise to span such as $1 / 8$, $1 / 6,1 / 5,1 / 4$ and 0.3 are considered in turn to analyze. The relationship curves of the maximum of absolute values of member's dynamic internal forces with the change of ratio of rise to span are showed in figure 3 , in which " $\mathrm{X}$ ", "Y", " $\mathrm{Z}$ " and "XYZ"
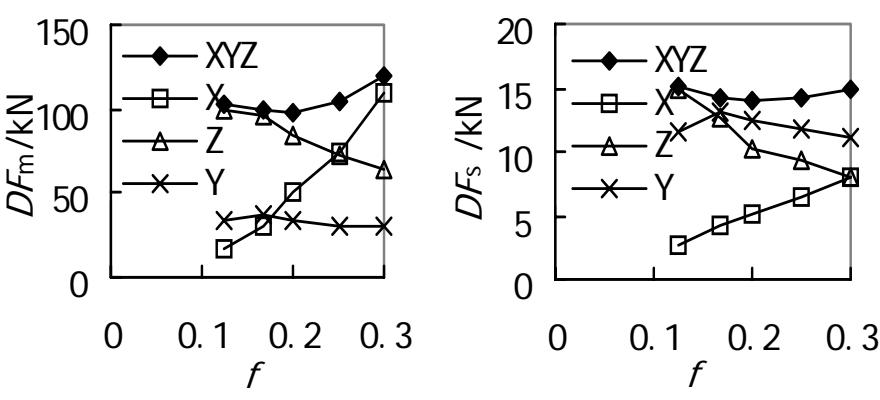

Figure 3. Relationship between maximum of absolute value of dynamic internal forces and ratio of rise to span - $f$

represent the horizontal transverse, horizontal longitudinal, vertical one-dimensional and three-dimensional earthquake action respectively, $D F_{\mathrm{m}}$ and $D F_{\mathrm{s}}$ represent the maximum of absolute values of members' dynamic internal forces in main structure and sub-structures respectively. The codes used in the following text have the same meaning. From the figure we can see that with the increase of ratio of rise to span, the $D F_{\mathrm{m}}$ and $D F_{\mathrm{s}}$ under vertical earthquake action decline gradually, but the $D F_{\mathrm{m}}$ and $D F_{\mathrm{s}}$ under x-one-dimensional earthquake action increase gradually. The $D F_{\mathrm{m}}$ and $D F_{\mathrm{s}}$ under y-one-dimensional earthquake action also decline gradually except within the range of very small ratio of rise to span. The change extents of the $D F_{\mathrm{m}}$ are small comparatively and that of the $D F_{\mathrm{s}}$ are large comparatively. With the increase of ratio of rise to span, the $D F_{\mathrm{m}}$ and $D F_{\mathrm{s}}$ under three-dimensional earthquake action decrease slightly at first then increase gradually, and reach their minimum value when $f=1 / 5$. So the cylindrical LITDBS reticulated mega-structure with plane-plate grids sub-structures has the best seismic property when its ratio of rise to span takes value of $1 / 5$.

\subsection{Influence of height of the $3 d$ latticed beam $-h$}

In the same way, suppose that $S=100 \mathrm{~m}$, $f=1 / 5, h s=1.2 \mathrm{~m}$, then different values of height of 3d latticed beams such as 2.0, 2.5, 3.0, 3.5 and $4.0 \mathrm{~m}$ are considered in turn to analyze. The relationship curves of the maximum of absolute values of member's dynamic internal forces with the change of $h$ are showed in figure 4 . From the figure we can see that, under $\mathrm{x}$-one-dimensional earthquake action, the $D F_{\mathrm{m}}$ decreases gradually and the
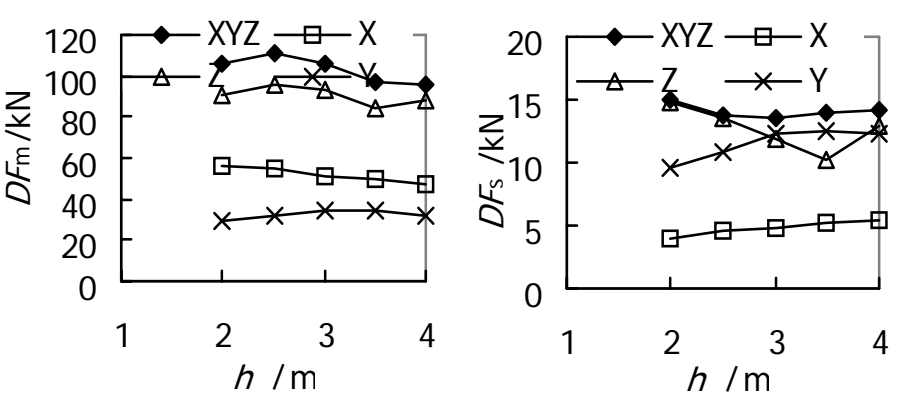

Figure 4. Relationship between maximum of absolute value of dynamic internal forces and height of 3d latticed beam - $h$ 
$D F_{\mathrm{s}}$ increases gradually with the increase of $h$. Under vertical one-dimensional earthquake action, the maximum of absolute value of members' dynamic internal forces fluctuate with the change of $h$, and the $D F_{\mathrm{m}}$ and $D F_{\mathrm{s}}$ are all at their minimum value when $h$ takes value close to $3.5 \mathrm{~m}$. Under horizontal longitudinal $(\mathrm{Y})$ one-dimensional earthquake action, the $D F_{\mathrm{m}}$ does not change a lot, but the $D F_{\mathrm{s}}$ increases gradually at first with the increase of $h$ and does not change any more when $h$ arrives to above $3 \mathrm{~m}$. Under three-dimensional earthquake action, the $D F_{\mathrm{m}}$ decreases gradually with increase of $h$ except $h$ is very small (less than $2.5 \mathrm{~m}$ ) and does not change any more when $h$ arrive to above $3.5 \mathrm{~m}$. The $D F_{\mathrm{s}}$ decrease gradually at first then increase a little with increase of $h$, but all the changes are not very large.

\subsection{Influence of thickness of sub-structure - hs}

Suppose that $S=100 \mathrm{~m}, f=1 / 5, h=3.5 \mathrm{~m}$, then diffenrent values of thickness of sub-structure such as 1.0, 1.2, 1.4 and $1.6 \mathrm{~m}$ are considered in turn to analyze. The results are showed in Figure 5, from which we can see that, the $D F_{\mathrm{m}}$ under $\mathrm{x}$-one-dimensional, $\mathrm{y}$-onedimensional, z-one-dimensional and three-dimensional earthquake actions increases gradually with increase of thickness of sub-structure. The $D F_{\mathrm{s}}$
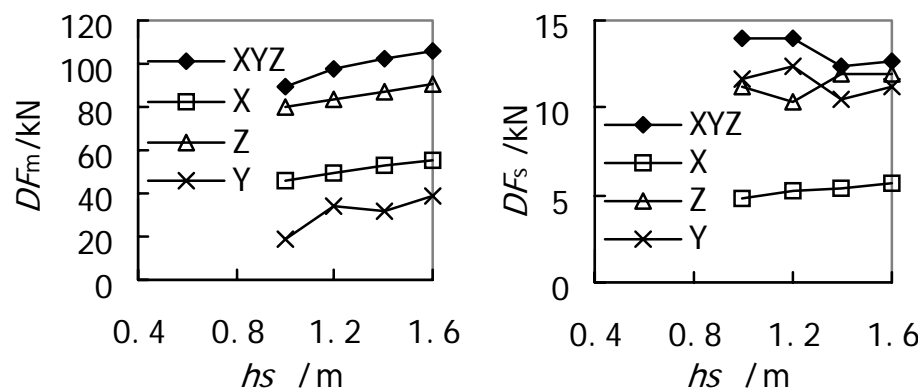

Figure 5. Relationship between maximum of absolute value of dynamic internal forces and thickness of sub-structures - hs under x-one-dimensional earthquake action increases gradually, and that under z-one-dimensional, $\mathrm{y}$-one-dimensional or three-dimensional earthquake actions fluctuate with the increase of thickness of sub-structure, but as a whole, the $D F_{\mathrm{s}}$ under y-one-dimensional and three-dimensional earthquake actions has the trend of decrease and that under z-one-dimensional earthquake actions has the trend of increase.

\subsection{Influence of ratio of length to span of main structure - LS}

Suppose that $L=80 \mathrm{~m}, f=1 / 5, h=3 \mathrm{~m}$, $m=4, \quad S \mathrm{~m}=\Phi 180 \times 10, \quad h s=1.2 \mathrm{~m}$, Ss $=\Phi 76 \times 4$, Load $=1 \mathrm{kN} / \mathrm{m}^{2}$; then the following values of number of longitudinal big rids are considered to analyze: 2, 4, 5 and 7 , the corresponding length of main structure are 46.063, 92.126, 115.157 and $161.220 \mathrm{~m}$ respectively, and the corresponding ratio of length to span of main structure are $0.576,1.152$, 1.439 and 2.015. The calculating results are show in Figure 6.
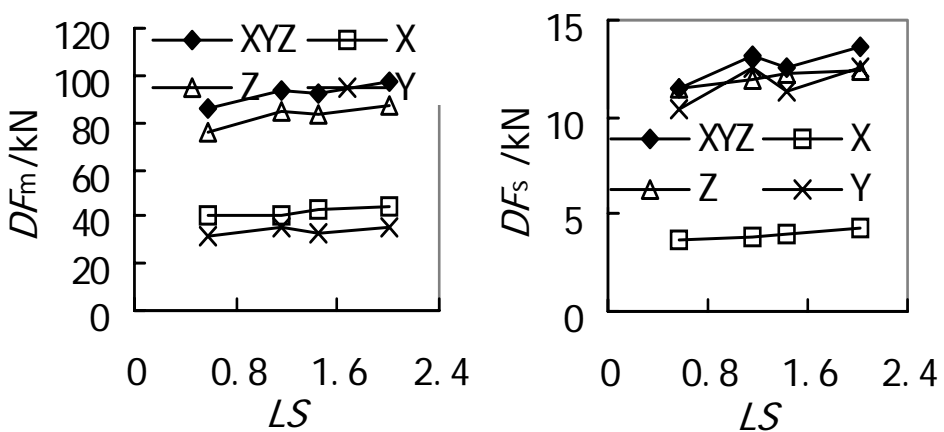

Figure 6. Relationship between maximum of absolute value of dynamic internal forces and ratio of length to span of main structures - $L S$

From the figure we can see that, with the increase of ratio of length to span of the main structure, the $D F_{\mathrm{m}}$ under y-one-dimensional earthquake action almost has no change, and that under $\mathrm{x}$-one-dimensional, z-one-dimensional or three-dimensional earthquake action has the trend of increase but the changes are very small. The $D F_{\mathrm{s}}$ under x-one-dimensional or z-one-dimensional earthquake action has the trend of gradual increase, and that under y-one-dimensional or 
three-dimensional earthquake action has the trend of fluctuating increase, but all the changes are very small. In a word, the influence of ratio of length to span of the main structure on the maximum of absolute value of dynamic internal forces is small comparatively.

\section{CONCLUSION}

This paper is focused on the research of seismic response of cylindrical (LITDBS) reticulated mega-structure with double-layers grid sub-structures using response spectrum technique. The distribution laws of dynamic internal forces of elements in its main structure and sub-structures are researched firstly. Reasonable vibration modes combination of vibration mode-decompositionresponse-spectra method is discussed. Seismic behaviors of the structure under different directional seismic loads are analyzed; therefore the reasonable required components of seismic loads for aseismic design are obtained. A series of parameter analysis are carried out at last. The main conclusions are as follows.

1) As the main bearing components, the ratios of dynamic internal forces to static internal forces in upper and lower chord members of the arched 3d latticed beams are almost kept within 0.1, which proves that the seismic property of this structure is good. Though the ratios of dynamic internal forces to static internal forces in some upper diagonal bracing members, upper cross-bars, web members of the arched $3 d$ latticed beams and many members of the longitudinal 3d latticed beams are high, their dynamic internal forces and static internal forces are all very small, which make it possible to design these members according to constructional demands.

2) While calculating the seismic internal forces using mode-decomposition-response spectra method, if the first nine vibration modes are considered, the errors of dynamic internal forces in main bearing members are kept within 5 percent, which can almost meet the needs. If possible we can consider the first sixteen vibration modes and the errors of dynamic internal forces in main bearing members are kept within 1 percent.

3) Generally three-dimensional earthquake action should be considered for the seismic checking calculation of this structure. But on condition of the main structure bearing the load cooperatively with substructures, for the dynamic and static internal forces in web members of substructures are all small and they can be designed according to constructional demands, we can lay emphasis on the seismic checking calculation of the main structure and the chord members of substructures and can only consider two-dimensional earthquake action combination of transverse horizontal and vertical components.

All the works will provide guides in theory for the use of this new structure, but the elastic-plastic performances and the broken rules under keen earthquakes are needful to be more researched.

\section{ACKNOWLEDGEMENTS}

This work was financially supported by the National Natural Science Foundation of China under Grant No. 50508013, which is gratefully acknowledged. 


\section{REFERENCES}

[1] He Yongjun, "Research on structural form, static and stability of latticed mega-structure [D]”, Zhejiang University, 2001.

[2] He Yongjun, Zhou Xuhong and Dong Shilin, "Research on mega-structure braced with sub-structures of double layer grids”, China Civil Engineering Journal, 2002, 35(6), pp.24-43.

[3] He Yongjun, "Research on dynamic property, seismic response and simplified analysis method of reticulated mega-structure [R]”, Hunan University, 2003.

[4] Shen Jumin, Zhou Xiyuan, Gao Xiaowang and Liu Jingbo, “Aseismic Engineering”, China Architecture \& Building Press, 2000.

[5] Ministry of Construction P.R. China, "Code for Seismic Design of Buildings", China Architecture \& Building Press, 2001.

[6] He Yongjun, Zhou Xuhong and Dong Shilin, "Research on dynamic characteristic of cylindrical latticed intersected three-dimensional beam system reticulated mega-structure with Double Layer Sub-structure”, Building Science, 2003, 19(5), pp.10-15.

[7] Anagnostopoulos, S.A., "Response Spectrum Techniques for Three-Component Earthquake Design”, Earthquake Engineering and Structural Dynamics, 1981, 9(4). 